\title{
Comunicación responsable en infografías digitales publicadas por empresas farmacéuticas
}

\section{Responsible communication in digital infographics published by pharmaceutical companies}

Recibido: 01/07/2020

Aceptado: 05/10/2020

Publicado: 30/11/2020
Paola Eunice Rivera Salas paola.rivera@correo.buap.mx https://orcid.org/0000-0002-8050-3585 Benemérita Universidad Autónoma de Puebla (México)

Hilda Gabriela Hernández Flores hgabriela.hernandez@correo.buap.mx https://orcid.org/0000-0002-3896-9090 Benemérita Universidad Autónoma de Puebla (México)

Resumen: Actualmente, las organizaciones utilizan infográficos en las redes sociales para tener mayor impacto en los públicos. En ese sentido, se tiene como objetivo caracterizar la presencia de la comunicación responsable en infografías publicadas por empresas farmacéuticas en la red social Facebook. La metodología que se desarrolla es cuantitativa, descriptiva, transversal y no experimental. La variable de interés fue la comunicación responsable (CR) en dos subcampos: "comunicación corporativa" y "comunicación digital" (Hernández-Flores, 2018). Se observaron 69 infografías publicadas por 4 empresas farmacéuticas multinacionales que cuentan con sitio oficial en dicha red en 2018. En cuanto a la comunicación digital, la infografía es una herramienta de comunicación efectiva, aunque la interactividad que surge de dicha publicación no es atendida por las empresas observadas. Sobre la comunicación corporativa, se promueve la cultura corporativa en los infográficos, no así la 
reputación de las compañías analizadas. Así, es prioritario detectar las áreas de oportunidad que tienen las organizaciones para ejercer una CR hacia sus públicos mediante herramientas digitales.

Palabras clave: Comunicación responsable, Comunicación corporativa, Comunicación digital, Infografías, Redes sociales.

Abstract: Organizations currently use infographics on social media to have a greater impact on audiences. Objective: Characterize the presence of Responsible Communication in infographics published by pharmaceutical companies on the social network Facebook. Methodology: Quantitative, descriptive, transversal, and non-experimental. The variable of interest was Responsible Communication (CR) in two subfields: Corporate Communication and Digital Communication (Hernández-Flores, 2018). 69 infographics published by 4 multinational pharmaceutical companies that had an official website in said network in 2018 were observed. Results: As for Digital Communication, infographics are an effective communication tool; although, the interactivity that arises from said publication is not attended by the observed companies. On Corporate Communication, corporate culture is promoted in infographics, but not the reputation of the companies analyzed. Conclusions: It is a priority to detect the areas of opportunity that organizations must execute a CR towards their audiences using digital tools.

Key words: Responsible communication, Corporative communication, Digital communication, Infographics, Social networks.

\section{Introducción}

En un mundo saturado de imágenes de diversa índole, las organizaciones compiten por la atención de sus públicos, especialmente en los espacios virtuales de las redes sociales. Martínez (2018) destaca que en México hay 79,1 millones de usuarios de Internet, lo que representa una penetración del 67\% de la población. De los más de 70 millones de internautas mexicanos, cerca del 95\%, son usuarios de la red social Facebook; otras redes que también se consumen son YouTube y Twitter, completando el top 3 (Excélsior, 2019). Según Maldonado (2016), 65,5 millones de esos usuarios, se conec- 
tan diariamente a Facebook, razón suficiente para que las organizaciones, sobre todo aquellas que tienen que ver con la venta de productos o servicios, quieran tener presencia en esta red social. Por ello, y considerando los costos publicitarios, las organizaciones se han replantado su estrategia comunicativa digital, desplazándose con mayor frecuencia hacia el uso de herramientas visuales que son altamente viables para su socialización en redes sociales.

Hoy se pueden encontrar en la red social de Facebook muchas páginas corporativas con esta intención. Según Smith (2019) se estima que existen 60 millones de páginas activas de negocios y 5 millones de anunciantes activos. De estos, Facebook representa el 53,1\% de los inicios de sesión en redes sociales realizados por los consumidores para acceder a aplicaciones y webs de publicistas y marcas (Maldonado, 2016). Las organizaciones han invadido esta red social teniendo como casi único objetivo lograr posicionamiento público en estos espacios. Paralelamente, se han aventurado a compartir gráficos y esquemas, que apoyan al usuario respecto a temas o procesos que, aunadas o soportadas por herramientas visuales, han logrado aporte al usuario. En este esquema, el área de la salud no es la excepción, ya que varias de las empresas farmacéuticas más destacadas por sus ingresos, en 2018, tienen una alta presencia en la red usando este tipo de herramientas (Gil, 2015).

Así, una de las unidades de información visual que ha tomado auge entre las organizaciones es la infografía. Este recurso visual tiene el propósito de educar a los usuarios mediante recursos visuales, al mismo tiempo que coloca a la empresa y el producto y/o servicio que proporcionan. Al respecto, Gil (2015) señala que 1 de cada 4 usuarios (al hacer una consulta sobre temáticas de salud) utiliza las redes sociales para seguir la experiencia de otros; y en el $41 \%$ de los casos, la información que reciben en los distintos formatos que publican las redes sociales influye en su elección de servicio o producto de salud.

La infografía (como un elemento gráfico que comunica) ha existido desde mucho tiempo atrás. No obstante, es en los años 50 cuando su uso se empieza a masificar a raíz de la inserción de la publicidad en medios impresos como los periódicos y revistas (De Pablos, 1998). Hasta este siglo, con la evolución de la web 2.0, la infografía se da a conocer (en primera instancia) por periódicos a través de sus plataformas digitales. Las versiones digitales de estos medios daban a conocer una nota periodística a través de esta estructura grá- 
fica y fueron agregaron elementos multimedia para facilitar la información al receptor (Salaverría, 2004).

\subsection{Comunicación corporativa}

La comunicación en cualquiera de sus modalidades ha sido un elemento de relevancia para vincular y afianzar las relaciones con los receptores clave, ya sean clientes, ciudadanos, autoridades, usuarios o entidades. Por lo que la comunicación en el área corporativa juega un papel importante en la construcción y correcta emisión de los mensajes institucionales. Diversos han sido los autores que han definido a la comunicación corporativa: para Capriotti (citado en Apolo et al., 2017, p. 526) la comunicación corporativa es "la totalidad de los recursos de comunicación de los que dispone una organización para llegar efectivamente a sus públicos”. Por su parte, Costa (1995) menciona que este tipo de comunicación es holística e integradora, es decir, que en ella se coordinan, se integran y se gestionan las distintas formas de comunicación como un todo orgánico que expresa el sentido corporativo de la organización. Por su parte, Rincón $(2014$, p. 26) expresa que

la comunicación corporativa es el proceso que posibilita la interrelación del género humano a partir de diversidad signos estableciendo un código válido para el intercambio de ideas y conceptos, instando a la acción de los individuos, en consecuencia, con su pensamiento, garantizando la retroalimentación o retroacción de dicho proceso.

Tomando en cuenta su conceptualización es importante tener presente los elementos que la conforman: planificación de estrategias, mensaje, canal, receptor, decodificación y medición de los resultados. A continuación, hablaremos de la comunicación digital.

\subsection{Comunicación digital}

Es aquella comunicación que transmite información en diferentes formatos, teniendo como medio de base la Internet. Este tipo de comunicación ha representado un parteaguas en los modelos de comunicación por varias cuestiones. En primer lugar, la interactividad y los flujos de información se llevan a cabo 
a una velocidad cada vez más rápida. Esta característica se percibe como uno de los principales activos para individuos y organizaciones (Yepes, 2006). En los ambientes virtuales se han originado otros productos comunicativos que están orientados a distintas audiencias. Esto obliga a que las estrategias de comunicación estén en constante transformación.

Desde la perspectiva organizacional, la comunicación digital es vista como las acciones que un agente económico realiza a través de la Internet, aplicando herramientas digitales (Latuff \& Nakhoul, 2008). La comunicación mediada a través de recursos digitales ha generado espacios comunicativos que atienden a diferentes flujos de comunicación, que van desde uno a uno, de uno a muchos, de muchos a muchos o en grupos (Comba \& Toledo, 2008), todos estos logrados a partir de una inmensa gama de recursos usados o creadas hoy para espacios sociales colaborativos.

\subsection{Comunicación responsable $(\mathrm{CR})$}

Aunque los orígenes de este término pueden ubicarse junto con el desarrollo de la "responsabilidad social corporativa "en la década de 1980, para su comprensión es necesario abordar la CR como un campo independiente y emergente. Boshoff (2017) en una revisión de literatura que realizó sobre el concepto de "responsabilidad corporativa", establece que la conceptualización de la CR conlleva el desafío inmediato de que tanto la responsabilidad como la comunicación carecen de definiciones universalmente aceptadas que surgen de conceptualizaciones diversas e incluso contradictorias. Actualmente, la CR ha sido definida por Hernández-Flores (2018) en diferentes presentaciones y publicaciones académicas, donde la establece como:

un diálogo comprometido entre la organización y sus audiencias, que se espera sea honesto, congruente y, por lo tanto, responsable, dando así una gestión comprometida de la organización, no sólo con la marca, el producto o el servicio sino con todos los aspectos del acto comunicativo.

Bajo esa conceptualización se encuentra en desarrollo un modelo que, dados sus elementos, es aplicable a organizaciones, profesiones y medios digitales (Figura 1). 


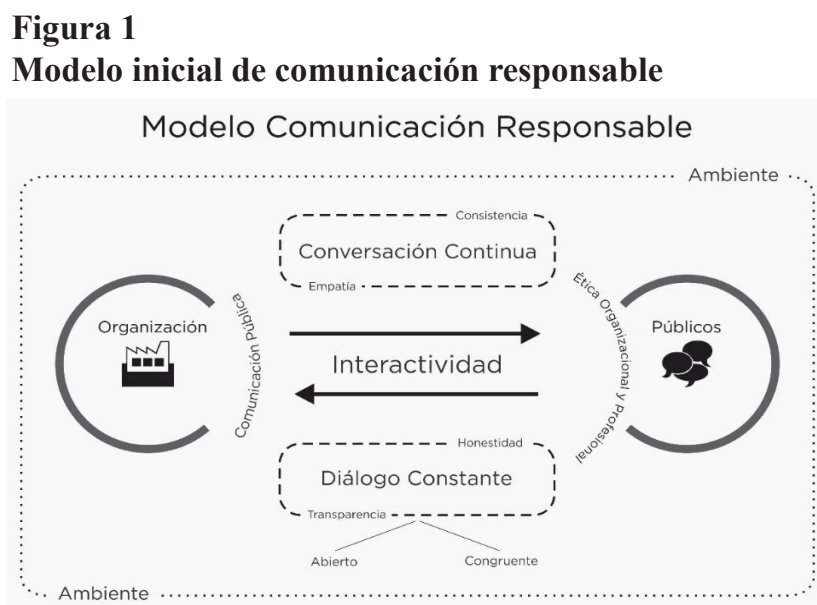

Nota: Elaboración propia.

Dicho modelo contempla 5 rasgos básicos para que exista CR: "honestidad", "empatía", "transparencia", "interactividad" y "consistencia" (elementos que son expuestos en la Figura 1) y un cuadro de subcampos que propone los rasgos generales más los particulares de cada área de la comunicación que se ha trabajado bajo esta perspectiva (Figura 2).

Figura 2

Cuadro de subcampos de CR

\begin{tabular}{|c|c|c|}
\hline $\begin{array}{l}\text { Rasgos de la } \\
\text { Comunicación } \\
\text { Responsable }\end{array}$ & Sub campos & $\begin{array}{c}\text { Rasgos } \\
\text { Complementarios }\end{array}$ \\
\hline Honestidad & $\begin{array}{c}\text { Comunicación Corporativa } \\
\text { e Institucional }\end{array}$ & $\begin{array}{l}\text { - Imagen } \\
\text { - Reputación } \\
\text { - Cultura organizacional }\end{array}$ \\
\hline Empatía & $\begin{array}{c}\text { Comunicación } \\
\text { Gubernamental y Política }\end{array}$ & $\begin{array}{l}\text { - Participación Ciudadana } \\
\text { - Compromiso } \\
\text { - Pro Legitimidad Gubernamental }\end{array}$ \\
\hline Transparencia & & \\
\hline Interactividad & Comunicación Digital & $\begin{array}{l}\text { - Herramientas Digitales } \\
\text { - Fiabilidad } \\
\text { - Validez de la Investigación } \\
\text { - Fuentes }\end{array}$ \\
\hline Consistencia & Comunicación Educativa & $\begin{array}{l}\text { - Pedagogia Critica } \\
\text { - Recursos didácticos } \\
\text { - Proceso de Aprendizaje } \\
\text { - Habilidades Discursivas }\end{array}$ \\
\hline
\end{tabular}

Nota: Elaboración propia.

De esta manera, la CR es un factor clave en el proceso de creación de credibilidad y, por ende, de legitimidad de las organizaciones y, a la vez, de las herramientas que utiliza para comunicarse con sus públicos. De ahí que se plantee 
como un proceso de diálogo abierto, en el que hay continua interactividad y retroalimentación de parte de la audiencia y de la organización, logrando así una comunicación basada en la confianza de todas las partes. El objetivo de este diálogo abierto es fortalecer las relaciones con sus audiencias aumentando el nivel de confianza de todos para así alcanzar sus objetivos. Por lo que

el papel de la comunicación es mantener, proteger o mejorar el valor percibido de las partes interesadas clave a través de la persuasión y la construcción positiva de la marca, así como desviar cualquier información que pueda socavar el valor de la reputación. (Glozer et al., 2018, p. 5)

La CR con sus elementos aporta mucho a ello. Así, los efectos esperados y los objetivos de la CR están vinculados a la percepción de las partes a través de una comunicación pública que permite generar una reputación sustentada y que se logra a través de atender los rasgos mencionados del modelo. Como contribución a esta perspectiva García-Marzá (2017) rescata las aportaciones de Habermas llamadas "reclamos de validez" (honestidad, verdad y justicia) y explica:

Estas declaraciones de validez también nos ayudan a recordar que debemos hacer que todos los procesos de producción y transmisión de información estén sujetos a estas condiciones, que son la base de todos los procesos comunicativos y definen la comunicación responsable. (p. 270)

Por lo que, si bien las funciones de CR pueden variar ligeramente según el sector de la organización o la herramienta digital, siempre estarán vinculadas a una perspectiva ética que apoya una comunicación trasparente, honesta y empática de las organizaciones con sus públicos y con su entorno.

\subsubsection{Subcampo comunicación corporativa}

Dentro de la perspectiva de CR, la comunicación corporativa es vista como la comunicación que emana de la organización hacia los públicos a través de cualquier forma o herramienta, que es congruente a la filosofía corporativa $y$, por ende, deja entrever una gestión responsable de la marca, el discurso, el producto o el servicio, hacia su entorno, logrando así legitimidad y reputación. De este tipo de comunicación se desprenden 3 rasgos específicos adicionales, que a continuación se muestran en la Figura 3. 
Figura 3

Rasgos específicos de la CR corporativa e institucional

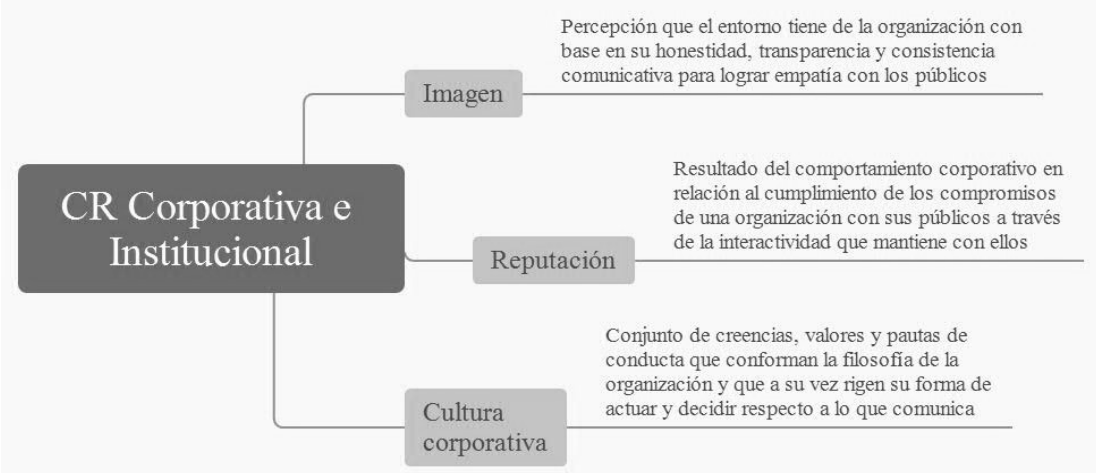

Nota: Elaboración propia.

\subsubsection{Subcampo comunicación digital}

Es el tipo de comunicación que tiene lugar a partir del uso de la Internet, propiciando que la información y el conocimiento veraces sean el principal insumo para las audiencias que atienden (cada día) nuevos códigos, canales y formatos digitales en los que se comunican de forma fluida los receptores a través de fuentes confiables. Sus rasgos pueden ser observados en la figura 4 .

\section{Figura 4}

Rasgos específicos de la CR Digital

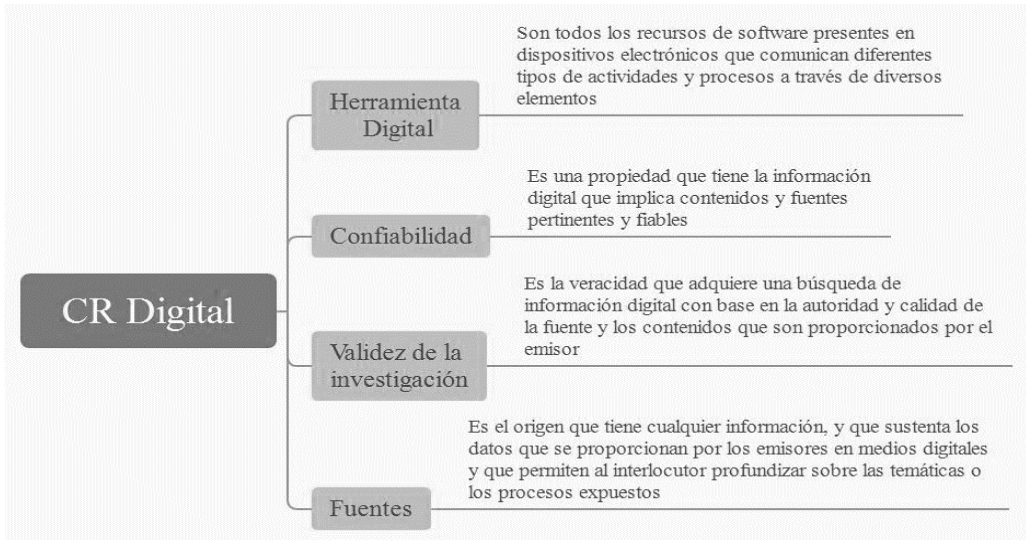

Nota: Elaboración propia. 
A partir de estos subcampos de CR, la investigación se concentra en la presencia de estos en las herramientas digitales, que son todos los recursos de software presentes en los dispositivos electrónicos que comunican diferentes tipos de conocimientos, actividades y procesos a través de diversos elementos. Estos recursos se definen como programas intangibles que se pueden visualizar en cualquier dispositivo electrónico y que tienen el objetivo de facilitar las tareas de la vida cotidiana al lograr que la información sea asequible para cualquier usuario digital (Vázquez, 2017).

Así, con el desarrollo de la web 2.0, han surgido un sinfín de herramientas digitales que hoy funcionan como insumos de las organizaciones, los profesionistas y los medios digitales para la difusión de información mediante gráficos, animaciones o cualquier elemento multimedia que genera la propia organización (Barriga \& Andrade, 2012). Por su parte Grané \& Bartolomé (2008) mencionan que las herramientas digitales permiten la distribución y socialización de información en el espacio virtual, por lo que estos recursos han impactado la manera en que las empresas llevan a cabo sus labores cotidianas de comunicación.

\subsection{Herramientas digitales en redes sociales: infografías}

El uso de la herramienta digital ha permitido que la comunicación pase de ser unidireccional a ser multidireccional, ya que facilita el proceso de feedback en los distintos espacios como es el caso de las redes sociales. Las redes sociales son entornos que permiten hacer comunidades de diferente índole. Debido a esto, facilitan la creación de relaciones y la acción de compartir contenidos que atienden a una gran gama de intereses de los consumidores y campos específicos que hay en la red (Grané \& Bartolomé, 2008).

Las herramientas digitales han contribuido al incremento de publicaciones y espacios de difusión. Asimismo, existen recursos digitales que ejecutan procesos de selección y relevancia de información. Sin embargo, al mismo tiempo, existen indicadores que ayudan a vislumbrar la validez de una búsqueda en la Internet. Algunos criterios que sobresalen son: quién es el responsable de la información, la relevancia y alcance de los datos, el contenido y su exactitud, entre otros (Kriscautzky \& Ferreriro, 2014), indicadores que se retoman en este trabajo para el análisis de infografías farmacéuticas (Figura 5). 
Figura 5

Características observadas en las herramientas digitales
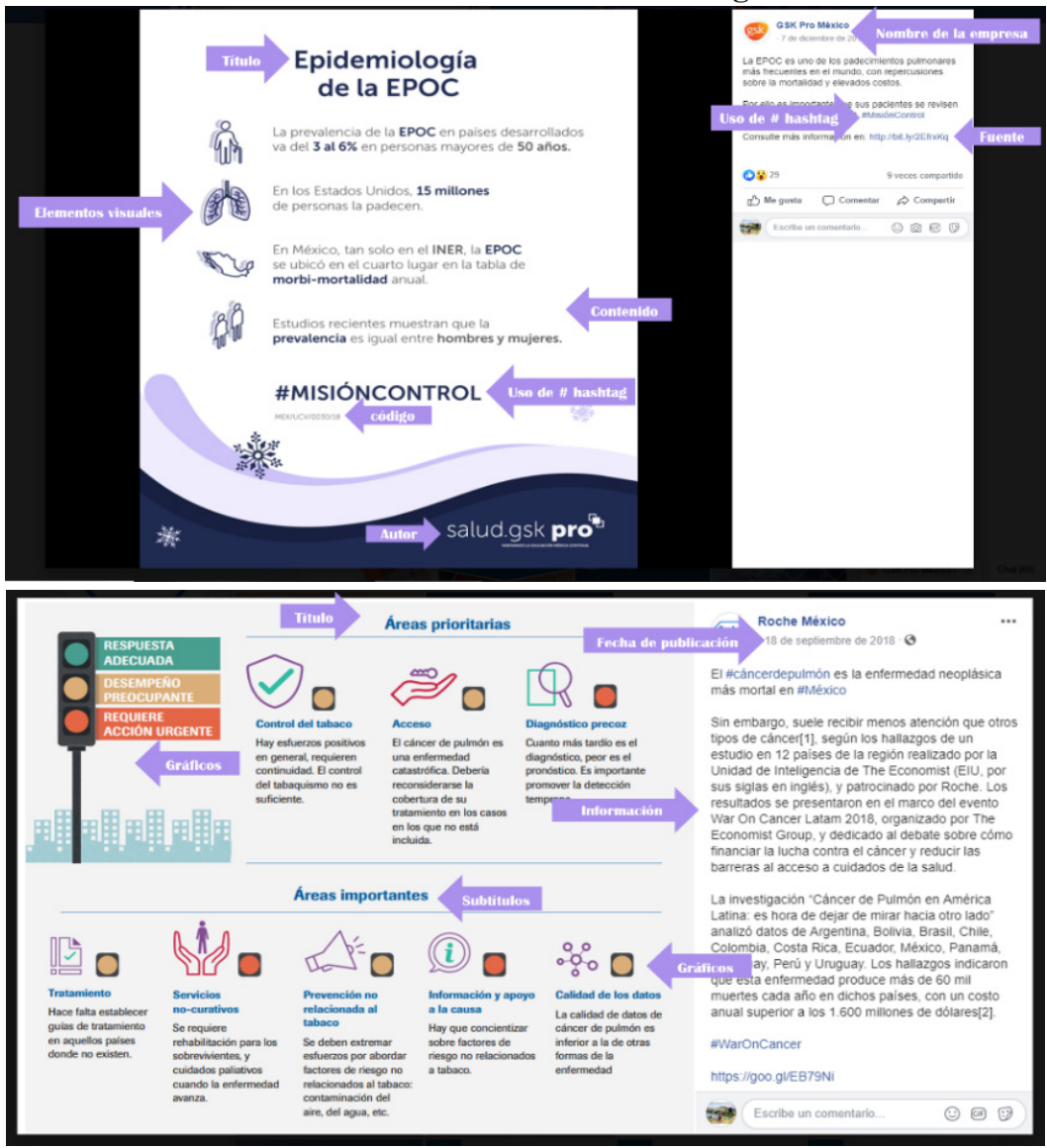

Nota: Cuentas oficiales de Facebook de GSK Pro México (7/XII/2018) y Roche México (18/IX/2018).

La infografía es una combinación de elementos visuales, gráficos y atractivos para el receptor, de fácil lectura, que se utiliza fundamentalmente para difundir información compleja en un formato sencillo (Marín, 2009). Como herramienta digital (y ante públicos con una alta tendencia por los productos comunicativos visuales) el infográfico ha tenido un auge significativo, ya que se ha venido ocupando como recurso periodístico, educativo y casi por cualquier organización que pretende dar un mensaje de manera rápida y eficiente (Muñoz del Bosque, 2017). A su vez, es un elemento visual que permite la socialización de contenidos de manera versátil y accesible a los distintos públicos y audiencias que existen en la Internet (Rivera, 2019). 
Otra característica es que pueden aglutinar varios elementos visuales y texto de forma conjunta y armónica. Además de ser un medio de prevención y promoción de bajo costo y con un gran alcance a públicos con distintos niveles de alfabetización tradicional y digital (González-Pacanowski \& Medina, 2009). Es así como el infográfico constituye no solo un producto comunicativo, sino que denota su intención de informar y educar al quién lo consume, de forma sencilla y en un corto tiempo (García García, 2006).

Tabakman (2011) destaca puntos clave que deben ser considerados para la elaboración de las infografías. Por un lado, subraya la importancia de la mención de fuentes de información legibles. Estas fuentes deben ser reconocidas en el área temática que la herramienta aborda. Igualmente, si se trata algún tema científico, debe mantener el rigor correspondiente, sin implementar tecnicismos complejos o mensajes poco comprensibles para la audiencia. Por lo tanto, cualquiera que sea el tópico que aborden, deben elaborarse con absoluto apego a la ética profesional, utilizando datos reales y recientes publicados por autoridades en el tema, y/o que realicen investigación al respecto. Aunque los responsables del diseño y realización de los infográficos pueden echar mano de la creatividad, la información será presentada de forma comprensible y fundamentada (Muñoz del Bosque, 2017). Entonces, se puede precisar que la herramienta digital conocida como infografía ha encontrado un espacio adecuado para su difusión redes sociales. Su alta demanda se ha favorecido por el interés que los recursos visuales han generado entre los públicos, en este caso los organizacionales.

Considerando lo anterior, este trabajo tiene por objetivo caracterizar la presencia de comunicación responsable en infografías publicadas por empresas farmacéuticas en la red social Facebook.

\section{Metodología}

Para esta investigación se aplicó un enfoque cuantitativo, ya que se recolectaron datos numéricos para su posterior análisis estadístico descriptivo. Asimismo (como únicamente se muestra el comportamiento de los subcampos de la variable, tal cual sucede, sin injerencia o manipulación sobre ellas) el estudio es de tipo descriptivo y no experimental. Adicionalmente, se recuperó información sobre un periodo específico de tiempo, en concreto, las info- 
grafías que se publicaron en los sitios oficiales de Facebook de las empresas farmacéuticas que se dieron a conocer durante 2018 a través de este espacio virtual; y los datos se recuperaron durante el segundo trimestre de 2019, de ahí que se hable de una investigación transversal.

La variable abordada en esta investigación es la comunicación responsable, que bajo el modelo expuesto (Hernández-Flores, 2018) y concretamente los subcampos de comunicación corporativa y comunicación digital, permiten estructurar el análisis infográfico que sirve de base para caracterizar el objeto de estudio.

Así, sobre la base del ranking de IgeaHub (2019) del nivel de inversión y ventas, se identificaron las 10 empresas farmacéuticas más importantes para efectos de este estudio. La Tabla 1 precisa el listado de las empresas del ramo que reportaron las más altas cifras a nivel mundial, siendo estos indicadores un punto de partida para la delimitación de los objetos de estudio que se integrarían en esta investigación.

\section{Tabla 1}

Ranking de empresas farmacéuticas en el mundo según su ranking de inversión y ventas en 2018

\begin{tabular}{|r|l|r|r|r|r|}
\hline \multicolumn{2}{|c|}{} & $\begin{array}{r}\text { Ventas en } \\
\text { segmento } \\
\text { ftico. 2017 }\end{array}$ & $\begin{array}{c}\text { Inversión } \\
\text { I+D 2017 }\end{array}$ & $\begin{array}{c}\text { \% Crecim. } \\
\text { Ventas } \\
\text { farma 16/17 }\end{array}$ & $\begin{array}{l}\text { \% de ventas } \\
\text { farma sobre } \\
\text { venta total }\end{array}$ \\
\hline 1 & Roche & 44.368 & 10.392 & 12,34 & 77,33 \\
\hline 2 & Pfizer & 52.540 & 7.657 & $-0,53$ & 100,00 \\
\hline 3 & Abbvie & 28.216 & 4.982 & 10,39 & 100,00 \\
\hline 4 & J\&J & 36.256 & 10.554 & 8,34 & 47,42 \\
\hline 5 & Sanofi & 36.663 & 6.697 & 4,20 & 85,44 \\
\hline 6 & Merck \& co. & 35.390 & 10.000 & 1,00 & 88,23 \\
\hline 7 & Novartis & 33.000 & 8.972 & 1,35 & 67,19 \\
\hline 8 & Gilhead & 25.662 & 3.374 & $-15,55$ & 100,00 \\
\hline 9 & GSK & 24.038 & 6.235 & 7,00 & 57,16 \\
\hline 10 & Amgen & 22.849 & 3.562 & $-1,00$ & 100,00 \\
\hline
\end{tabular}

Nota: Cifras en millones de dólares. IgeaHub (2019).

Posteriormente, se cotejó que las empresas contarán con sitio oficial de Facebook para México. Sólo 4 de ellas cumplían con esta característica. Estas son: GSK, Pfizer, Novartis y Roche México. El resto de las compañías cuentan 
con página oficial en dicha red social, pero enfocadas hacia otra zona geográfica (es decir, son sitios globales o regionales). La descripción del sitio de Facebook de las empresas mencionadas se detalla en la Tabla 2.

Tabla 2

Descripción de los sitios de Facebook de las empresas farmacéuticas

\begin{tabular}{|c|c|c|c|c|}
\hline $\begin{array}{l}\text { Nombre de } \\
\text { la Empresa }\end{array}$ & GSK & Novartis & Pfizer & Roche \\
\hline Descripción & $\begin{array}{l}\text { GSK ProMéxico } \\
\text { es una multipla- } \\
\text { taforma exclusi- } \\
\text { va que le ofrece } \\
\text { a los profesiona- } \\
\text { les de la salud } \\
\text { las herramientas } \\
\text { indispensables } \\
\text { para mantener- } \\
\text { se actualizados. }\end{array}$ & $\begin{array}{l}\text { Somos una com- } \\
\text { pañía global con } \\
\text { base en Suiza en } \\
\text { la que buscamos } \\
\text { descubrir nuevos } \\
\text { caminos para } \\
\text { prolongar y mejo- } \\
\text { rar la vida de los } \\
\text { pacientes en el } \\
\text { mundo. }\end{array}$ & $\begin{array}{l}\text { Pfizer México utiliza } \\
\text { los famosos hashtags } \\
\text { para conmemorar las } \\
\text { efemérides con la leyen- } \\
\text { da "Día Mundial de...", } \\
\text { citando que la OMS } \\
\text { proclama como oficiales } \\
\text { y más hashtags en cual- } \\
\text { quier fecha como son: } \\
\text { \#PfizerProud } \\
\text { \#SomosPfizer } \\
\text { \#ProfesionalesDeLaSalud }\end{array}$ & $\begin{array}{l}\text { Cuenta Oficial } \\
\text { de Roche Méxi- } \\
\text { co con noticias } \\
\text { y actualizacio- } \\
\text { nes sobre la } \\
\text { forma en que } \\
\text { trabajamos } \\
\text { para hacer que } \\
\text { la medicina } \\
\text { personalizada } \\
\text { sea una } \\
\text { realidad. }\end{array}$ \\
\hline $\begin{array}{l}\text { Fecha de } \\
\text { creación }\end{array}$ & $\begin{array}{c}5 \text { de marzo de } \\
2015\end{array}$ & $\begin{array}{c}21 \text { de julio de } \\
2016\end{array}$ & 26 de febrero de 2015 & $\begin{array}{c}9 \text { de febrero de } \\
2017\end{array}$ \\
\hline Sitio Web & $\begin{array}{c}\text { https://www.gsk. } \\
\text { com/en-gb/con- } \\
\text { tact-us/worldwi- } \\
\text { de/mexico/ }\end{array}$ & $\begin{array}{l}\text { https://www.novar- } \\
\text { tis.com.mx }\end{array}$ & $\begin{array}{l}\text { https://www.pfizer.com. } \\
\text { mx/ }\end{array}$ & $\begin{array}{l}\text { https://www. } \\
\text { roche.com.mx/ }\end{array}$ \\
\hline $\begin{array}{c}\text { Nombre del } \\
\text { sitio } \\
\text { Facebook }\end{array}$ & $\begin{array}{l}\text { GSK ProMéxico } \\
@ \text { GSKProMx }\end{array}$ & $\begin{array}{l}\text { Novartis México } \\
\text { @novartisméxico }\end{array}$ & $\begin{array}{l}\text { Pfizer México } \\
@ \text { PfizerMX }\end{array}$ & $\begin{array}{l}\text { Roche México } \\
@ \text { @rocheméxico }\end{array}$ \\
\hline $\begin{array}{l}\text { Número de } \\
\text { seguidores }\end{array}$ & 20,542 & 15,712 & 20,608 & 20,815 \\
\hline $\begin{array}{l}\text { Número de } \\
\text { me gusta }\end{array}$ & 20,272 & 15,448 & 20,204 & 20,680 \\
\hline
\end{tabular}

Nota: Elaboración propia.

Teniendo claridad de cuáles eran las empresas por considerar, se identificaron los infográficos que fueron publicados durante 2018. Es así como se censaron un total de 69 infografías. No se aplicó algún muestreo, puesto que el tamaño de la población es pequeña y fácilmente se podían consultar estos elementos en la red social Facebook, así que se trabajó con el total de los productos comunicativos difundidos durante el periodo señalado. Es importante mencionar que estas empresas no solo publican infografías en su página oficial: también difunden otros elementos visuales como gifs, videos y fotografías de manera periódica. 
Para la recolección de datos se utilizó una guía de observación que incluye la variable propuesta y los rasgos mencionados para su estudio. La aplicación de este instrumento implicó verificar la presencia de los elementos de la CR a través de los 49 ítems distribuidos entre los rasgos generales y los rasgos específicos (Tabla 3). Cabe señalar que el instrumento aplicado es el resultado de un piloteo que se realizó con 4 observadores previamente capacitados, quienes validaron la guía de observación mediante una revisión infografías similares. Luego de ello, se ejecutó el mismo ejercicio, hasta llegar a los ítems en los que todos los observadores coincidieron en la medición. Las características recuperadas de las herramientas observadas aparecen ilustradas en la Tabla 3. Los datos fueron procesados y se calcularon indicadores estadísticos descriptivos (porcentajes y gráficos) mediante el uso de la paquetería Excel.

\section{Tabla 3}

Operacionalización de variables

\begin{tabular}{|c|c|c|c|c|c|c|c|c|}
\hline Objetivo & 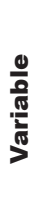 & Definición & 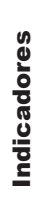 & Definición & 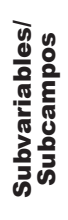 & 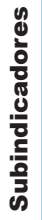 & Ítems & $\frac{5}{0}$ \\
\hline \multirow{11}{*}{$\begin{array}{l}\text { Describir la } \\
\text { presencia } \\
\text { de comu- } \\
\text { nicación } \\
\text { respon- } \\
\text { sable en } \\
\text { infografías } \\
\text { publica- } \\
\text { das por } \\
\text { empresas } \\
\text { farmacéu- } \\
\text { ticas en } \\
\text { su página } \\
\text { oficial de la } \\
\text { red social } \\
\text { Facebook }\end{array}$} & \multirow{11}{*}{ 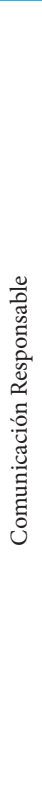 } & \multirow{11}{*}{$\begin{array}{l}\text { Es la } \\
\text { comunicación } \\
\text { honesta y } \\
\text { congruente } \\
\text { que se esta- } \\
\text { blece entre la } \\
\text { organización } \\
\text { y sus públicos, } \\
\text { y se refrenda } \\
\text { con gestión y } \\
\text { acciones com- } \\
\text { prometidas, } \\
\text { con base en } \\
\text { ello, se logra } \\
\text { una relación } \\
\text { de confianza } \\
\text { que asegura la } \\
\text { aceptación y } \\
\text { trascendencia } \\
\text { de la } \\
\text { organización }\end{array}$} & \multirow{8}{*}{ 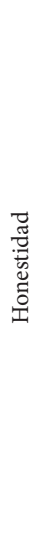 } & \multirow{8}{*}{$\begin{array}{l}\text { Se refiere a la } \\
\text { posibilidad } \\
\text { de verificar lo } \\
\text { que comunica } \\
\text { una organiza- } \\
\text { ción a través } \\
\text { de datos e } \\
\text { información } \\
\text { oficial, así } \\
\text { como las } \\
\text { referencias } \\
\text { proporcio- } \\
\text { nadas por el } \\
\text { emisor sobre } \\
\text { la posibilidad } \\
\text { de verificar lo } \\
\text { que se afirma. }\end{array}$} & \multirow{11}{*}{ 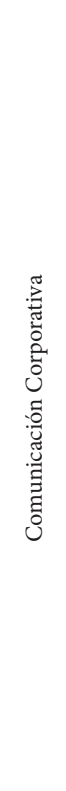 } & \multirow{7}{*}{ 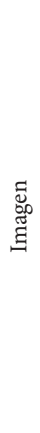 } & Favorece a la reputación de la empresa. & \multirow{11}{*}{ 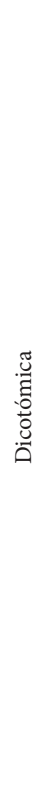 } \\
\hline & & & & & & & $\begin{array}{l}\text { Ayuda a legitimar la existencia de la empresa } \\
\text { ante sus consumidores. }\end{array}$ & \\
\hline & & & & & & & $\begin{array}{l}\text { Tiene un efecto positivo en el valor de las } \\
\text { marcas que tiene la empresa. }\end{array}$ & \\
\hline & & & & & & & Fomenta la credibilidad de la marca. & \\
\hline & & & & & & & $\begin{array}{l}\text { Contribuye a la buena imagen de la empresa } \\
\text { farmacéutica. }\end{array}$ & \\
\hline & & & & & & & $\begin{array}{l}\text { Favorece al incremento del nivel de confian- } \\
\text { za de la marca. }\end{array}$ & \\
\hline & & & & & & & Es acorde con el giro de la empresa & \\
\hline & & & & & & \multirow{4}{*}{ 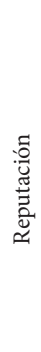 } & $\begin{array}{l}\text { Propicia la interactividad y la empatía con } \\
\text { los públicos a través de la información y } \\
\text { formato que aporta. }\end{array}$ & \\
\hline & & & \multirow{3}{*}{ 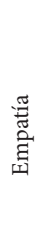 } & \multirow{3}{*}{$\begin{array}{l}\text { Implica en } \\
\text { mostrar } \\
\text { respeto por } \\
\text { la audiencia } \\
\text { al considerar } \\
\text { su contexto y } \\
\text { necesidades } \\
\text { específicas en }\end{array}$} & & & $\begin{array}{l}\text { Es acorde a la reputación corporativa de la } \\
\text { empresa en el mercado. }\end{array}$ & \\
\hline & & & & & & & $\begin{array}{l}\text { Contribuye a la reputación de empresa far- } \\
\text { macéutica como un medio de comunicación } \\
\text { responsable. }\end{array}$ & \\
\hline & & & & & & & $\begin{array}{l}\text { Muestra el compromiso de la empresa con } \\
\text { sus públicos. }\end{array}$ & \\
\hline
\end{tabular}




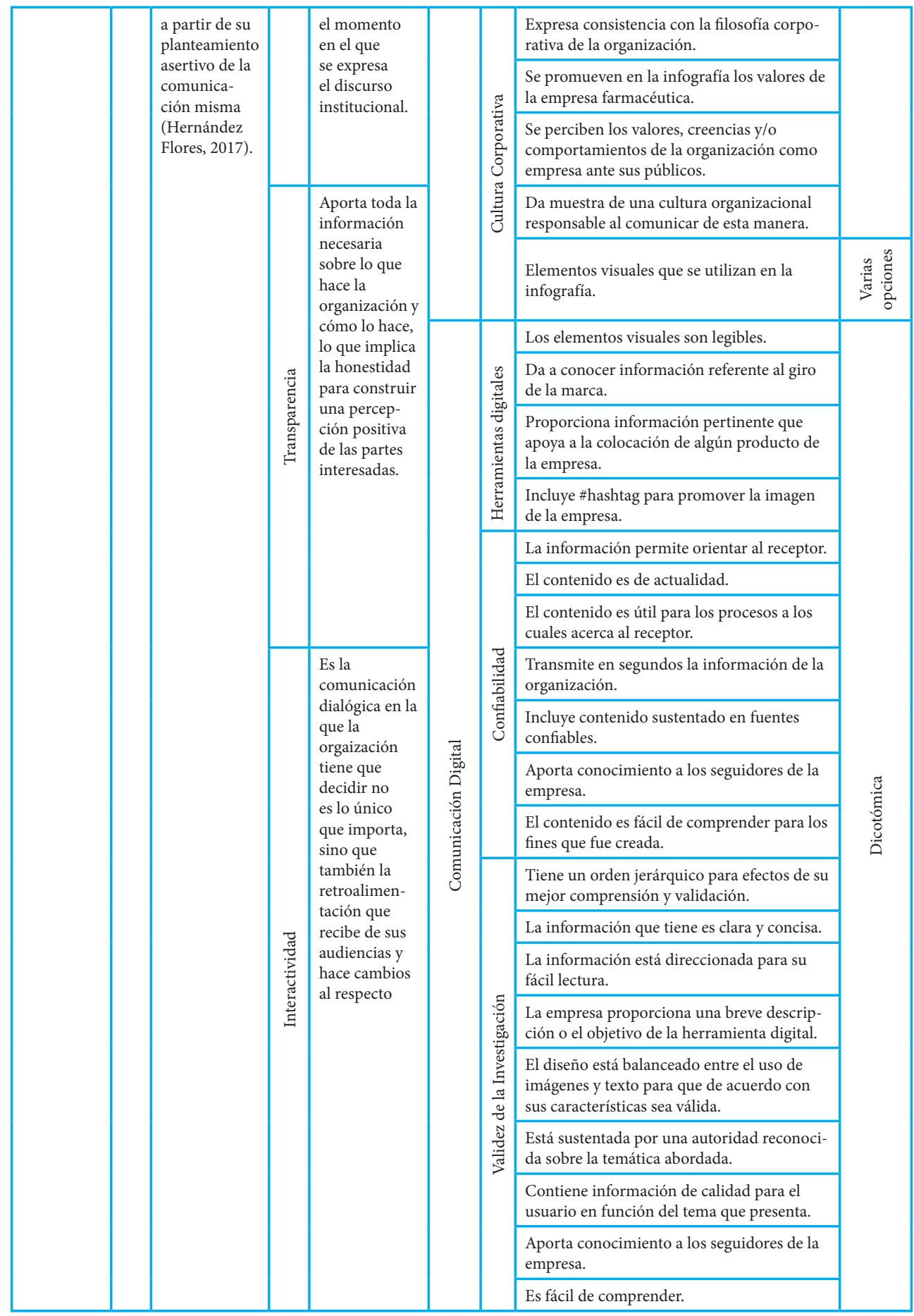




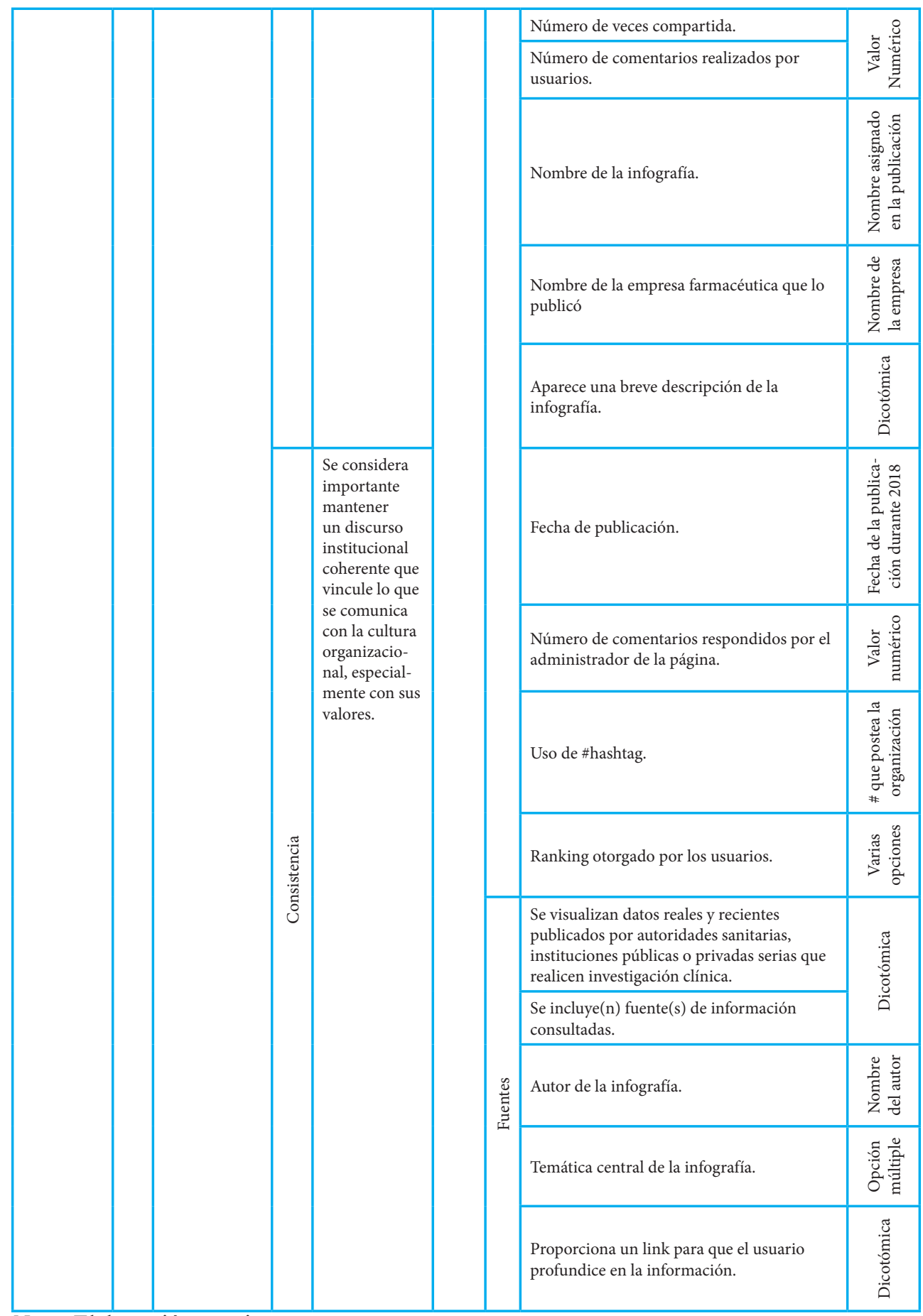

Nota: Elaboración propia.

ISSN: 2304-2265 


\section{Resultados}

Las 69 infografías, se concentran como sigue: 30 publicadas por GSK, 21 por Novartis, 7 por la empresa Pfizer y 11 por Roche México. El comportamiento de las publicaciones a lo largo de 2018 se observa en la Figura 6. Asimismo, se aprecia que no hay una práctica de publicación periódica de estos recursos en ninguna de las empresas; incluso hay meses del año que dejan de socializar infografías a sus públicos.

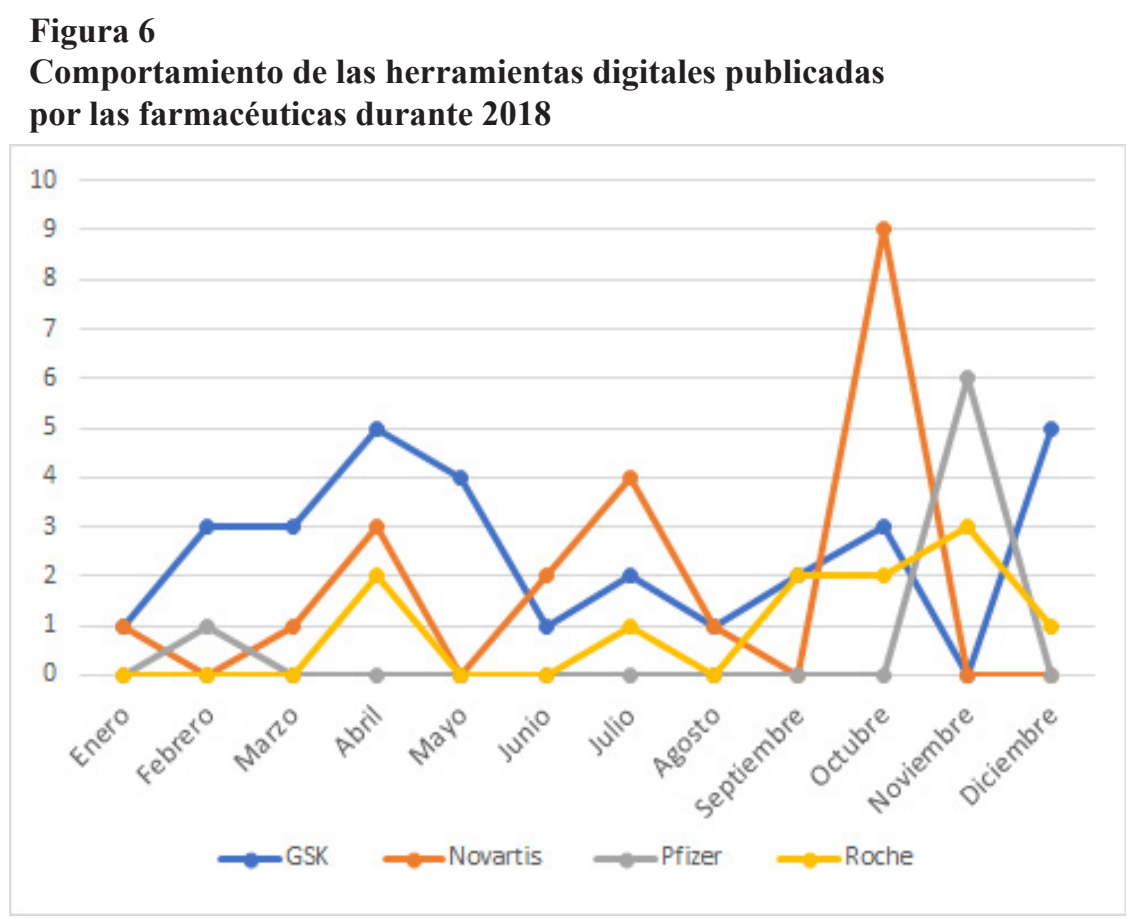

Nota: Elaboración propia.

En cuanto a la temática de las publicaciones, se detectó que la difusión de información sobre enfermedades es el tópico más recurrente. Resulta significativo que, en general, las empresas no utilizan este recurso para hacer recomendaciones sobre algún producto que generan. Igualmente, la empresa que presenta más variedad de temáticas es GSK, por lo que puede tener un mayor impacto en los públicos que atiende (Figura 7). 


\section{Figura 7}

Temática que abordan las infografías publicadas

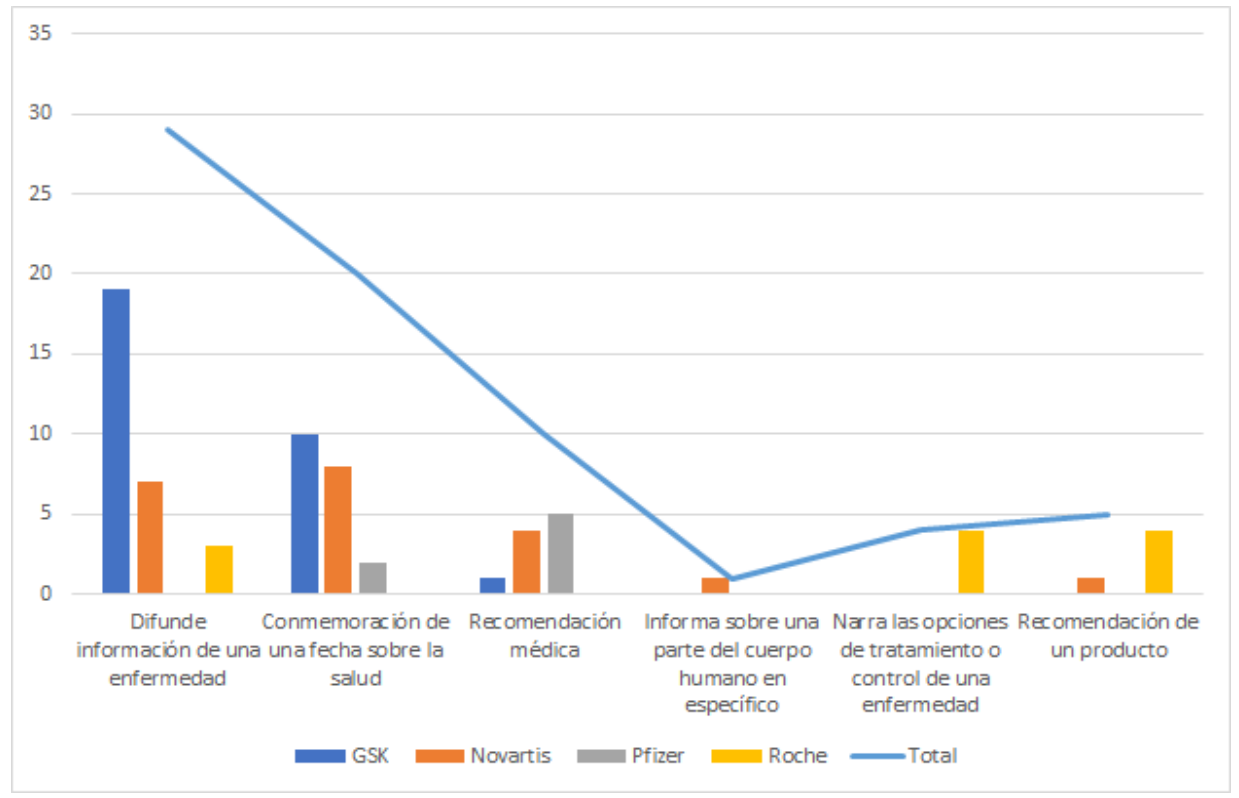

Nota: Elaboración propia.

\subsection{Comunicación responsable}

La interacción que presentan las empresas también fue medida. En promedio, se detectó que una publicación tiene 38 reacciones de distinto tipo. La reacción que es más recurrente es "Me gusta", seguido de "Me encanta". La reacción que no se manifiesta en algún caso es "Me divierte". La empresa que más reacciones tuvo fue Pfizer; lo que resulta representativo, pues fue la empresa que menos publicaciones hizo (Tabla 4). 
Tabla 4

Reacciones a las infografías

\begin{tabular}{|c|c|c|c|c|c|c|c|c|}
\hline $\begin{array}{c}\text { EMPRESA } \\
\text { FARMACÉUTICA }\end{array}$ & $\begin{array}{l}\text { INDICADOR } \\
\text { ESTADÍSTICO }\end{array}$ & $\begin{array}{l}\frac{\pi}{0} \\
\stackrel{0}{0} \\
\tilde{0} \\
\Sigma\end{array}$ & 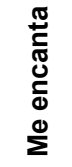 & 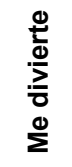 & $\begin{array}{l}\frac{\pi}{O} \\
\stackrel{\tau}{0} \\
0 \\
\mathbb{0}\end{array}$ & 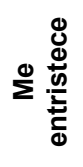 & 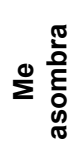 & $\begin{array}{c}\text { TOTAL DE } \\
\text { REACCIONES }\end{array}$ \\
\hline \multirow{3}{*}{ GSK } & Frec. total & 445 & 25 & 0 & 0 & 0 & 10 & \multirow{3}{*}{772} \\
\hline & promedio & 14.8 & 0.8 & 0.0 & 0.0 & 0.0 & 0.3 & \\
\hline & $\begin{array}{l}\text { Desviación } \\
\text { estándar }\end{array}$ & 7.8 & 0.9 & 0.0 & 0.0 & 0.0 & 0.7 & \\
\hline \multirow{3}{*}{ Novartis } & Frec. total & 245 & 11 & 0 & 1 & 2 & 2 & \multirow{3}{*}{349} \\
\hline & promedio & 11.7 & 0.5 & 0.0 & 0.0 & 0.1 & 0.1 & \\
\hline & $\begin{array}{l}\text { Desviación } \\
\text { estándar }\end{array}$ & 8.0 & 1.1 & 0.0 & 0.2 & 0.4 & 0.4 & \\
\hline \multirow{3}{*}{ Pfizer } & Frec. total & 509 & 44 & 0 & 1 & 2 & 3 & \multirow{3}{*}{1008} \\
\hline & promedio & 72.7 & 6.3 & 0.0 & 0.1 & 0.3 & 0.4 & \\
\hline & $\begin{array}{l}\text { Desviación } \\
\text { estándar }\end{array}$ & 52.9 & 4.1 & 0.0 & 0.4 & 0.5 & 0.8 & \\
\hline \multirow{3}{*}{ Roche } & Frec. total & 362 & 47 & 0 & 0 & 1 & 7 & \multirow{3}{*}{612} \\
\hline & promedio & 32.9 & 4.3 & 0.0 & 0.0 & 0.1 & 0.6 & \\
\hline & $\begin{array}{l}\text { Desviación } \\
\text { estándar }\end{array}$ & 33.0 & 5.5 & 0.0 & 0.0 & 0.3 & 1.4 & \\
\hline \multirow{3}{*}{ TOTAL GLOBAL } & Frec. total & 1561 & 127 & 0 & 2 & 5 & 22 & 2741 \\
\hline & promedio & 22.6 & 1.8 & 0.0 & 0.0 & 0.1 & 0.3 & 39.72 \\
\hline & $\begin{array}{l}\text { Desviación } \\
\text { estándar }\end{array}$ & 28.12 & 3.26 & 0.00 & 0.17 & 0.31 & 0.81 & 276.96 \\
\hline
\end{tabular}

Nota: Elaboración propia.

Complementario a lo anterior, hay una baja interacción de las empresas con los públicos. El censo mostró que se hacen pocos comentarios en general por los seguidores de las páginas de las empresas; esto es, menos de un comentario en promedio por publicación. Sin embargo, hay una casi nula respuesta de parte de los administradores sobre las pocas opiniones que emiten los usuarios, tan sólo 4 comentarios respondidos fueron ubicados en el total de las 69 infografías analizadas. Un elemento que se destaca de la empresa GSK, es que todos sus infográficos incluyen una clave que la empresa asigna, compuesta por las primeras letras de la palabra "México", las iniciales de la empresa, un número de control y el año de publicación. 


\subsubsection{Comunicación corporativa responsable}

En cuanto al subcampo "comunicación corporativa responsable", se analizaron 3 subindicadores: "imagen", "reputación" y "cultura corporativa". En este apartado se expresan los resultados que se encontrados a partir de la observación.

Atendiendo a la imagen, se aprecia que hay cuidado de parte de las empresas Novartis, Pfizer y Roche en dar continuidad a la imagen y ser congruentes en su identidad gráfica, no así GSK. Es significativo que las infografías observadas en todas las compañías analizadas se presentan de acuerdo con los parámetros de la filosofía corporativa, en un 93\% de los objetos de estudio observados (Tabla 5).

Tabla 5

Imagen

\begin{tabular}{|l|c|c|c|c|c|c|c|c|c|c|}
\hline \multirow{2}{*}{ Indicador } & \multicolumn{2}{|c|}{ GSK } & \multicolumn{2}{c|}{ Novartis } & \multicolumn{2}{c|}{ Pfizer } & \multicolumn{2}{c|}{ Roche } & \multicolumn{2}{c|}{$\begin{array}{c}\text { Total } \\
\text { global }\end{array}$} \\
\cline { 2 - 13 } & $\begin{array}{c}\% \\
\text { Sí }\end{array}$ & $\begin{array}{c}\% \\
\text { No }\end{array}$ & Sí & $\begin{array}{c}\% \\
\text { No }\end{array}$ & $\begin{array}{c}\% \\
\text { Sí }\end{array}$ & $\begin{array}{c}\% \\
\text { No }\end{array}$ & $\begin{array}{c}\% \\
\text { Sí }\end{array}$ & $\begin{array}{c}\% \\
\text { Sí }\end{array}$ & \begin{tabular}{c} 
No \\
\hline
\end{tabular} \\
\hline $\begin{array}{l}\text { El diseño de la herramienta digital apoya la } \\
\text { continuidad de buena imagen de la empre- } \\
\text { sa farmacéutica. }\end{array}$ & 33 & 67 & 95 & 5 & 100 & 0 & 100 & 0 & 70 & 30 \\
\hline $\begin{array}{l}\text { La imagen de la herramienta digital va } \\
\text { acorde a la identidad gráfica que tiene la } \\
\text { empresa en el mercado. }\end{array}$ & 27 & 73 & 90 & 10 & 100 & 0 & 100 & 0 & 65 & 35 \\
\hline $\begin{array}{l}\text { La herramienta ayuda a legitimar la marca } \\
\text { o producto de la empresa ante sus consu- } \\
\text { midores. }\end{array}$ & 33 & 67 & 86 & 14 & 86 & 14 & 100 & 0 & 65 & 35 \\
\hline $\begin{array}{l}\text { La herramienta digital tiene un efecto posi- } \\
\text { tivo en el valor de marca que tiene la em- } \\
\text { presa frente a sus públicos. }\end{array}$ & 37 & 63 & 86 & 14 & 100 & 0 & 100 & 0 & 68 & 32 \\
\hline $\begin{array}{l}\text { La información de la herramienta digital } \\
\text { apoya a la credibilidad de la marca. }\end{array}$ & 33 & 67 & 95 & 5 & 100 & 0 & 91 & 9 & 68 & 32 \\
\hline $\begin{array}{l}\text { La información de la herramienta digital in- } \\
\text { crementa el nivel de confianza de la marca } \\
\text { ante sus públicos. }\end{array}$ & 37 & 63 & 81 & 19 & 57 & 43 & 100 & 0 & 62 & 38 \\
\hline $\begin{array}{l}\text { La herramienta digital utilizada es acorde } \\
\text { con la filosofía corporativa de la organiza- } \\
\text { ción. }\end{array}$ & 93 & 7 & 86 & 14 & 100 & 0 & 100 & 0 & 93 & 7 \\
\hline
\end{tabular}

Nota: Elaboración propia. 
La reputación también fue medida en este ejercicio. De esta forma, se detectó que en 7 de cada 10 infografías evaluadas, la buena reputación de las empresas es promovida y proyectada. Este elemento de la comunicación corporativa es mayormente cuidado por la empresa Roche. En cambio, la empresa GSK reporta incongruencia en los mensajes que emite en sus infografías relacionados con su reputación corporativa, el nivel de compromiso y su CR con los usuarios (Tabla 6).

Tabla 6

Reputación

\begin{tabular}{|c|c|c|c|c|c|c|c|c|c|c|}
\hline \multirow{2}{*}{ Indicador } & \multicolumn{2}{|c|}{ GSK } & \multicolumn{2}{|c|}{ Novartis } & \multicolumn{2}{|c|}{ Pfizer } & \multicolumn{2}{|c|}{ Roche } & \multicolumn{2}{|c|}{$\begin{array}{c}\text { Total } \\
\text { global }\end{array}$} \\
\hline & $\begin{array}{l}\% \\
\mathrm{Si}\end{array}$ & $\begin{array}{l}\% \\
\text { No }\end{array}$ & $\begin{array}{l}\% \\
\mathrm{Si}\end{array}$ & $\begin{array}{l}\% \\
\text { No }\end{array}$ & $\begin{array}{l}\% \\
\mathrm{Si}\end{array}$ & $\begin{array}{l}\% \\
\text { No }\end{array}$ & $\begin{array}{l}\% \\
\mathrm{Si}\end{array}$ & $\begin{array}{l}\% \\
\text { No }\end{array}$ & $\begin{array}{l}\% \\
\mathrm{Si}\end{array}$ & $\begin{array}{l}\% \\
\text { No }\end{array}$ \\
\hline $\begin{array}{l}\text { La herramienta digital es acorde a la } \\
\text { reputación corporativa de la empresa } \\
\text { en el mercado. }\end{array}$ & 37 & 63 & 95 & 5 & 86 & 14 & 100 & 0 & 70 & 30 \\
\hline $\begin{array}{l}\text { La herramienta digital contribuye a la } \\
\text { reputación de empresa farmacéutica } \\
\text { como un medio de comunicación res- } \\
\text { ponsable. }\end{array}$ & 37 & 63 & 100 & 0 & 100 & 0 & 100 & 0 & 72 & 28 \\
\hline $\begin{array}{l}\text { La herramienta digital muestra el } \\
\text { compromiso de la empresa con sus } \\
\text { públicos. }\end{array}$ & 40 & 60 & 95 & 5 & 100 & 0 & 100 & 0 & 72 & 28 \\
\hline $\begin{array}{l}\text { La herramienta digital propicia la } \\
\text { interactividad y la empatía con los } \\
\text { públicos a través de la información y } \\
\text { formato que aporta. }\end{array}$ & 87 & 13 & 52 & 48 & 14 & 86 & 100 & 0 & 71 & 29 \\
\hline
\end{tabular}

Nota: Elaboración propia.

La tabla 7 contiene los resultados del subindicador de cultura corporativa. Asimismo, todos los indicadores tienen altos porcentajes de cumplimiento (mayores al 75\%). Únicamente 3 de las 4 empresas no aprovechan la publicación de infografías para insertar etiquetas (\#hashtags) que promuevan su filosofía corporativa. Por otro lado, la compañía Roche cuenta con mejores indicadores sobre este rasgo. 
Tabla 7

Cultura corporativa

\begin{tabular}{|c|c|c|c|c|c|c|c|c|c|c|}
\hline \multirow{2}{*}{ Indicador } & \multicolumn{2}{|c|}{ GSK } & \multicolumn{2}{|c|}{ Novartis } & \multicolumn{2}{|c|}{ Pfizer } & \multicolumn{2}{|c|}{ Roche } & \multicolumn{2}{|c|}{$\begin{array}{l}\text { Total } \\
\text { global }\end{array}$} \\
\hline & $\begin{array}{l}\% \\
\mathrm{Si}\end{array}$ & $\begin{array}{l}\% \\
\text { No }\end{array}$ & $\begin{array}{l}\% \\
\mathrm{Si}\end{array}$ & $\begin{array}{l}\% \\
\text { No }\end{array}$ & $\begin{array}{l}\% \\
\mathrm{Si}\end{array}$ & $\begin{array}{l}\% \\
\text { No }\end{array}$ & $\begin{array}{l}\% \\
\mathrm{Si}\end{array}$ & $\begin{array}{l}\% \\
\text { No }\end{array}$ & $\begin{array}{l}\% \\
\mathrm{Si}\end{array}$ & $\begin{array}{l}\% \\
\text { No }\end{array}$ \\
\hline $\begin{array}{l}\text { La herramienta digital expresa consis- } \\
\text { tencia con la filosofía corporativa de la } \\
\text { organización. }\end{array}$ & 97 & 3 & 86 & 14 & 57 & 43 & 100 & 0 & 90 & 10 \\
\hline $\begin{array}{l}\text { Se promueven de alguna manera en la } \\
\text { infografía los valores y/o creencias de } \\
\text { la empresa. }\end{array}$ & 97 & 3 & 81 & 19 & 100 & 0 & 91 & 9 & 91 & 9 \\
\hline $\begin{array}{l}\text { A través de la información proporciona- } \\
\text { da se perciben los valores, creencias } \\
\text { y/o comportamientos de la organiza- } \\
\text { ción como empresa ante sus públicos. }\end{array}$ & 100 & 0 & 71 & 29 & 86 & 14 & 91 & 9 & 88 & 12 \\
\hline $\begin{array}{l}\text { La herramienta digital incluye \#hashtag } \\
\text { para promover su cultura corporativa. }\end{array}$ & 20 & 80 & 24 & 76 & 14 & 86 & 91 & 9 & 32 & 68 \\
\hline $\begin{array}{l}\text { La herramienta digital da muestra de } \\
\text { una cultura organizacional responsable } \\
\text { al comunicar de esta manera. }\end{array}$ & 77 & 23 & 95 & 5 & 86 & 14 & 100 & 0 & 87 & 13 \\
\hline
\end{tabular}

Nota: Elaboración propia.

\subsubsection{Comunicación digital responsable}

En cuanto al tipo de elemento visual que aparecen en las infografías analizadas, se aprecia que el recurso más usado son las ilustraciones, seguido de las fotografías, partiendo del análisis de las cuatro empresas. Sin embargo, sobresale que Novartis y Pfizer prefieren utilizar la fotografía como elemento visual, lo que implica una tendencia inversa (Figura 8). 


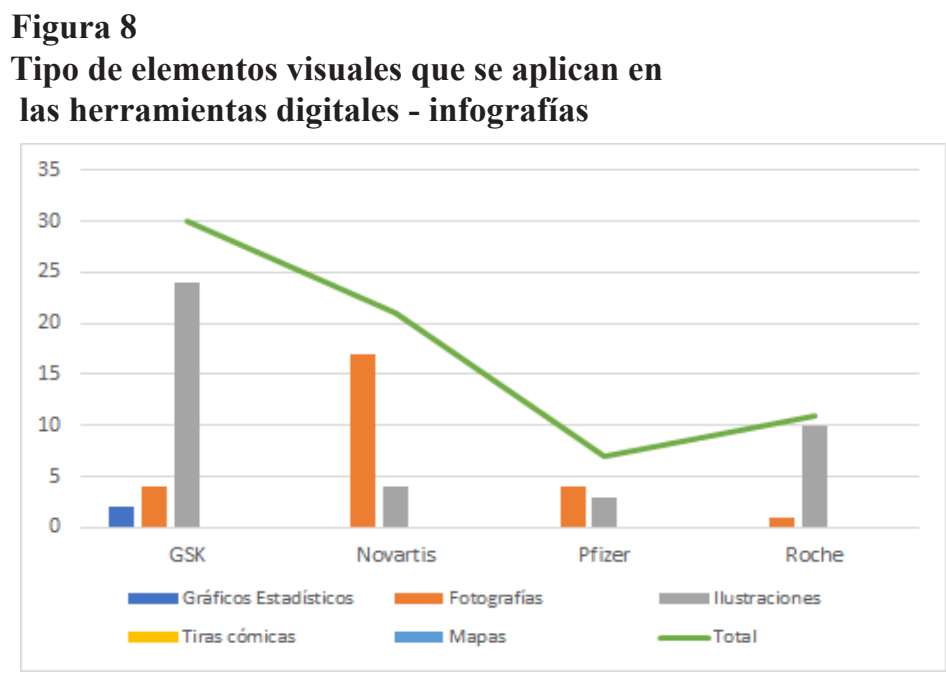

Nota: Elaboración propia.

Sobre la valoración general de la herramienta digital (infografía) desde el subcampo de la comunicación digital. Considerando que se midieron los elementos que contienen los infográficos y como ayudan a la promoción de la marca y sus productos, se percibe que en realidad esta herramienta digital no es implementada para socializar un producto $(57 \%$ de recurrencia en ambos ítems). Este comportamiento se presenta en todas las empresas que se observaron en este estudio, como se visualiza en la Tabla 8.

Tabla 8

Herramienta digital

\begin{tabular}{|c|c|c|c|c|c|c|c|c|c|c|}
\hline \multirow{2}{*}{ Indicador } & \multicolumn{2}{|c|}{ GSK } & \multicolumn{2}{|c|}{ Novartis } & \multicolumn{2}{|c|}{ Pfizer } & \multicolumn{2}{|c|}{ Roche } & \multicolumn{2}{|c|}{$\begin{array}{l}\text { Total } \\
\text { Global }\end{array}$} \\
\hline & $\begin{array}{l}\% \\
\mathrm{Si}\end{array}$ & $\begin{array}{l}\% \\
\text { No }\end{array}$ & $\begin{array}{l}\% \\
\mathrm{Si}\end{array}$ & $\begin{array}{l}\% \\
\text { No }\end{array}$ & $\begin{array}{l}\% \\
\mathrm{Si}\end{array}$ & $\begin{array}{l}\% \\
\text { No }\end{array}$ & $\begin{array}{l}\% \\
\mathrm{Si}\end{array}$ & $\begin{array}{l}\% \\
\text { No }\end{array}$ & $\begin{array}{l}\% \\
\mathrm{Si}\end{array}$ & $\begin{array}{l}\% \\
\text { No }\end{array}$ \\
\hline $\begin{array}{l}\text { La herramienta digital da a conocer in- } \\
\text { formación referente al giro de la marca. }\end{array}$ & 47 & 53 & 76 & 24 & 86 & 14 & 27 & 73 & 57 & 43 \\
\hline $\begin{array}{l}\text { Los elementos visuales son legibles que } \\
\text { se ocupan en la herramienta digital. }\end{array}$ & 77 & 23 & 100 & 0 & 100 & 0 & 100 & 0 & 90 & 10 \\
\hline $\begin{array}{l}\text { La herramienta digital proporciona } \\
\text { información pertinente que apoya a } \\
\text { la colocación de algún producto de la } \\
\text { empresa. }\end{array}$ & 43 & 57 & 67 & 33 & 43 & 57 & 82 & 18 & 57 & 43 \\
\hline $\begin{array}{l}\text { La herramienta digital incluye \#hashtag } \\
\text { para promover la imagen de la empresa. }\end{array}$ & 13 & 87 & 14 & 86 & 14 & 86 & 100 & 0 & 28 & 72 \\
\hline
\end{tabular}

Nota: Elaboración propia. 
Los hashtags (\#) también son un elemento que se aplica de forma recurrente en las infografías que se observaron. Pero se utilizan de forma distinta. En el caso de GSK implementan el \#MisionControl y \#Asma, para la colocación de productos relacionados con problemas del sistema respiratorio, área en la que son líderes en el mercado. Lo mismo sucede con Novartis, quien implementa el \#PídeleATuDerma, en la difusión de productos relacionados con la piel; y \#RocheOncología, para la promoción de la prevención contra el cáncer. En contraste Roche México inserta su \#RocheMéxico para posicionar la marca en sus publicaciones de infografías ante sus públicos (Tabla 9).

\section{Tabla 9}

Hashtgs que se implementan para difundir la temática abordada en la herramienta

\begin{tabular}{|c|c|c|}
\hline $\begin{array}{c}\text { Nombre de la empresa } \\
\text { farmacéutica que lo publicó }\end{array}$ & \#hashtag que incluye la infografía & Frec. \\
\hline \multirow{11}{*}{ GSK } & \#Parkinson & 1 \\
\hline & \#Hemofilia & 1 \\
\hline & \#Todas las meningitis importan & 1 \\
\hline & \#DiamundialdelaHemofiia & 1 \\
\hline & \#Diamundialdelapoblación & 1 \\
\hline & \#DíaDelVoluntariadoHospitalario & 1 \\
\hline & \#PsoSerious & 1 \\
\hline & \#VIHDA & 1 \\
\hline & \#VacunarseEsVivirSeguro & 1 \\
\hline & \#MisiónControl & 3 \\
\hline & \#Asma & 3 \\
\hline \multirow{7}{*}{ Novartis } & \#HablemosDePsoriasis & 1 \\
\hline & \#DíaMundialDeLaLeucemiaMieloideAguda & 1 \\
\hline & \#PídeleATuDerma & 3 \\
\hline & \#PorqueYoImporto & 1 \\
\hline & \#ExamínateATiempo & 1 \\
\hline & \#DíaMundialContraLaNeumonía & 1 \\
\hline & \#DíaMundialDelCáncer & 1 \\
\hline Pfizer & \#SabíasQué & 1 \\
\hline \multirow{6}{*}{ Roche } & \#DíaNacionalvsCáncerdePulmón & 1 \\
\hline & \#RochePressDay & 1 \\
\hline & \#linfomafolicular & 1 \\
\hline & \#cáncerdepulmón & 1 \\
\hline & \#ReimaginaLaHemofilia & 3 \\
\hline & \#RocheMéxico & 3 \\
\hline
\end{tabular}




\begin{tabular}{|l|l|c|}
\hline \multirow{y}{*}{} & \#RespirarYVivir & 1 \\
\cline { 2 - 3 } & \#RocheOncología & 5 \\
\cline { 2 - 3 } & \#DiaMundialLinfoma & 1 \\
\cline { 2 - 3 } & \#México & 1 \\
\cline { 2 - 3 } & \#WarOnCancer & 1 \\
\hline
\end{tabular}

Nota: Elaboración propia.

La confiabilidad también es un elemento importante en la comunicación digital responsable. Este subindicador tiene varios indicadores: el más relevante es escasa implementación de fuentes confiables en sus infográficos, con $39 \%$ de aparición de la herramienta digital revisada. Otras áreas de atención es que el contenido sea útil para el receptor y que la información se transmita de manera ágil (Tabla 10).

\section{Tabla 10}

Confiabilidad

\begin{tabular}{|c|c|c|c|c|c|c|c|c|c|c|}
\hline \multirow{2}{*}{ Indicador } & \multicolumn{2}{|c|}{ GSK } & \multicolumn{2}{|c|}{ Novartis } & \multicolumn{2}{|c|}{ Pfizer } & \multicolumn{2}{|c|}{ Roche } & \multicolumn{2}{|c|}{$\begin{array}{l}\text { Total } \\
\text { global }\end{array}$} \\
\hline & $\begin{array}{l}\% \\
\mathrm{Si}\end{array}$ & $\begin{array}{l}\% \\
\text { No }\end{array}$ & $\begin{array}{l}\% \\
\mathrm{Si}\end{array}$ & $\begin{array}{l}\% \\
\text { No }\end{array}$ & $\begin{array}{l}\% \\
\mathrm{Si}\end{array}$ & $\begin{array}{l}\% \\
\text { No }\end{array}$ & $\begin{array}{l}\% \\
\mathrm{Si}\end{array}$ & $\begin{array}{l}\% \\
\text { No }\end{array}$ & $\begin{array}{l}\% \\
\mathrm{Si}\end{array}$ & $\begin{array}{l}\% \\
\text { No }\end{array}$ \\
\hline $\begin{array}{l}\text { La información que contiene la herramienta } \\
\text { digital permite orientar al receptor. }\end{array}$ & 90 & 10 & 90 & 10 & 57 & 43 & 82 & 18 & 86 & 14 \\
\hline $\begin{array}{l}\text { El contenido de la herramienta digital es de } \\
\text { actualidad. }\end{array}$ & 43 & 57 & 95 & 5 & 86 & 14 & 91 & 9 & 71 & 29 \\
\hline $\begin{array}{l}\text { El contenido de la herramienta digital es } \\
\text { útil para los procesos a los cuales acerca al } \\
\text { receptor. }\end{array}$ & 57 & 43 & 67 & 33 & 29 & 71 & 100 & 0 & 64 & 36 \\
\hline $\begin{array}{l}\text { La herramienta transmite en segundos la } \\
\text { información de la organización. }\end{array}$ & 47 & 53 & 71 & 29 & 57 & 43 & 91 & 9 & 62 & 38 \\
\hline $\begin{array}{l}\text { La herramienta digital incluye contenido } \\
\text { sustentado en fuentes confiables. }\end{array}$ & 30 & 70 & 38 & 62 & 57 & 43 & 55 & 45 & 39 & 61 \\
\hline $\begin{array}{l}\text { La herramienta aporta conocimiento a los } \\
\text { seguidores de la empresa. }\end{array}$ & 93 & 7 & 95 & 5 & 57 & 43 & 100 & 0 & 91 & 9 \\
\hline $\begin{array}{l}\text { El contenido de la herramienta digital es } \\
\text { fácil de comprender para los fines que fue } \\
\text { creada. }\end{array}$ & 100 & 0 & 100 & 0 & 100 & 0 & 100 & 0 & 100 & 0 \\
\hline
\end{tabular}

Nota: Elaboración propia. 
Por otra parte, el subindicador validez de la información contenida en los infográficos, es evidente que, en términos generales, hay una presentación pertinente de la información (texto e imágenes) y es de alta calidad. Estos indicadores obtuvieron altos porcentajes para todas las empresas (mayores a $70 \%$ ). Además, GSK y Roche son las empresas que presentan el nivel más alto de validez de información en sus infografías. No obstante, la información que se coloca no está sustentada por alguna autoridad sanitaria o de investigación reconocida lo que denota las fuentes usadas. Estos indicadores se desglosan con mayor precisión en la Tabla 11.

\section{Tabla 11}

Validez

\begin{tabular}{|c|c|c|c|c|c|c|c|c|c|c|}
\hline \multirow{2}{*}{ Indicador } & \multicolumn{2}{|c|}{ GSK } & \multicolumn{2}{|c|}{ Novartis } & \multicolumn{2}{|c|}{ Pfizer } & \multicolumn{2}{|c|}{ Roche } & \multicolumn{2}{|c|}{$\begin{array}{l}\text { Total } \\
\text { global }\end{array}$} \\
\hline & $\begin{array}{l}\% \\
\mathrm{Si}\end{array}$ & $\begin{array}{c}\% \\
\text { No }\end{array}$ & $\begin{array}{l}\% \\
\mathrm{Si}\end{array}$ & $\begin{array}{c}\% \\
\text { No }\end{array}$ & $\begin{array}{l}\% \\
\mathrm{Si}\end{array}$ & $\begin{array}{l}\% \\
\text { No }\end{array}$ & $\begin{array}{l}\% \\
\mathrm{Si}\end{array}$ & $\begin{array}{c}\% \\
\text { No }\end{array}$ & $\begin{array}{l}\% \\
\mathrm{Si}\end{array}$ & $\begin{array}{l}\% \\
\text { No }\end{array}$ \\
\hline $\begin{array}{l}\text { La información contenida en la } \\
\text { herramienta digital tiene un orden } \\
\text { jerárquico para efectos de su mejor } \\
\text { comprensión y validación. }\end{array}$ & 100 & 0 & 95 & 5 & 71 & 29 & 82 & 18 & 93 & 7 \\
\hline $\begin{array}{l}\text { La información que tiene la } \\
\text { herramienta digital es clara } \\
\text { y concisa. }\end{array}$ & 100 & 0 & 100 & 0 & 71 & 29 & 100 & 0 & 97 & 3 \\
\hline $\begin{array}{l}\text { La información de la herramienta } \\
\text { digital está direccionada para su } \\
\text { fácil lectura. }\end{array}$ & 100 & 0 & 100 & 0 & 71 & 29 & 100 & 0 & 97 & 3 \\
\hline $\begin{array}{l}\text { La empresa proporciona una breve } \\
\text { descripción o el objetivo de la } \\
\text { herramienta digital. }\end{array}$ & 100 & 0 & 100 & 0 & 100 & 0 & 100 & 0 & 100 & 0 \\
\hline $\begin{array}{l}\text { El diseño de la herramienta digital } \\
\text { está balanceado entre el uso de } \\
\text { imágenes y texto para que de } \\
\text { acuerdo con sus características } \\
\text { sea válida. }\end{array}$ & 93 & 7 & 100 & 0 & 86 & 14 & 100 & 0 & 96 & 4 \\
\hline $\begin{array}{l}\text { La herramienta digital está susten- } \\
\text { tada por una autoridad reconocida } \\
\text { sobre la temática abordada. }\end{array}$ & 50 & 50 & 38 & 62 & 43 & 57 & 36 & 64 & 43 & 57 \\
\hline $\begin{array}{l}\text { La herramienta digital contiene infor- } \\
\text { mación de calidad para el usuario en } \\
\text { función del tema que presenta. }\end{array}$ & 83 & 17 & 67 & 33 & 43 & 57 & 100 & 0 & 77 & 23 \\
\hline
\end{tabular}

Nota: Elaboración propia. 
En la Tabla 12 se concentran los ítems relacionados con el subindicador fuentes. Cabe señalar que este subindicador es que obtuvo puntajes menores en esta investigación, en un rango de 3\% a 48\%. Es importante subrayar en este rubro que la hipertextualidad y los vínculos no son recursos que se ocupan para complementar el contenido de los infográficos, ya que tan solo el $3 \%$ de las publicaciones incluyen hipertexto y 28 un hipervínculo o link para profundizar la consulta sobre los temas que se comunican en la herramienta.

Tabla 12

Fuentes

\begin{tabular}{|c|c|c|c|c|c|c|c|c|c|c|}
\hline \multirow{2}{*}{ Indicador } & \multicolumn{2}{|c|}{ GSK } & \multicolumn{2}{|c|}{ Novartis } & \multicolumn{2}{|c|}{ Pfizer } & \multicolumn{2}{|c|}{ Roche } & \multicolumn{2}{|c|}{$\begin{array}{l}\text { Total } \\
\text { global }\end{array}$} \\
\hline & $\begin{array}{l}\% \\
\mathrm{Si}\end{array}$ & $\begin{array}{c}\% \\
\text { No }\end{array}$ & $\begin{array}{l}\% \\
\mathrm{Si}\end{array}$ & $\begin{array}{l}\% \\
\text { No }\end{array}$ & $\begin{array}{l}\% \\
\mathrm{Si}\end{array}$ & $\begin{array}{c}\% \\
\text { No }\end{array}$ & $\begin{array}{l}\% \\
\mathrm{Si}\end{array}$ & $\begin{array}{c}\% \\
\text { No }\end{array}$ & $\begin{array}{l}\% \\
\mathrm{Si}\end{array}$ & $\begin{array}{c}\% \\
\text { No }\end{array}$ \\
\hline $\begin{array}{l}\text { En la herramienta digital se visualizan datos } \\
\text { recientes publicados por autoridades sanita- } \\
\text { rias, instituciones públicas o privadas serias } \\
\text { que realizan investigación en el área. }\end{array}$ & 7 & 93 & 19 & 81 & 43 & 57 & 9 & 91 & 14 & 86 \\
\hline $\begin{array}{l}\text { La herramienta digital incluye las fuentes de } \\
\text { información consultadas. }\end{array}$ & 13 & 87 & 19 & 81 & 57 & 43 & 18 & 82 & 20 & 80 \\
\hline $\begin{array}{l}\text { La herramienta digital muestra el autor de la } \\
\text { infografía. }\end{array}$ & 27 & 73 & 71 & 29 & 14 & 86 & 82 & 18 & 48 & 52 \\
\hline $\begin{array}{l}\text { La herramienta digital integra hipervínculos } \\
\text { para incrementar la información que le da al } \\
\text { usuario. }\end{array}$ & 0 & 100 & 10 & 90 & 0 & 100 & 0 & 100 & 3 & 97 \\
\hline $\begin{array}{l}\text { La herramienta digital proporciona un link } \\
\text { para que el usuario profundice en la temática } \\
\text { o proceso. }\end{array}$ & 30 & 70 & 19 & 81 & 14 & 86 & 45 & 55 & 28 & 72 \\
\hline
\end{tabular}

Nota: Elaboración propia.

\section{Discusión}

En cuanto a la publicación de infografías por parte de las empresas farmacéuticas, se aprecia que sólo dos de las organizaciones reconocen el potencial que tienen estos elementos (GSK y Roche México). Asimismo, sobresale que no hay una frecuencia de publicación establecida por estas corporaciones al respecto de estos elementos gráficos. Esto puede conllevar a que no se promueva tanta interactividad y empatía con la audiencia como lo proponen Yepes (2006) y Latuff \& Nakhoul (2008). 
Un área de oportunidad que es importante de atender es propiciar el diálogo con los públicos. Es indispensable contrarrestar la falta de interacción con los seguidores de las páginas oficiales en cuanto a sus comentarios y reacciones se refiere y establecer un diálogo honesto. Hay que aprovechar el tipo de recurso de bajo costo y gran alcance a públicos digitales que González-Pacanowski \& Medina (2009) han señalado representan las herramientas digitales como las infografías y las redes sociales.

Desde la comunicación digital y la herramienta digital, es claro que las empresas no aplican a la infografía como un medio para promover la marca o alguno de los productos que involucran la gran gama que tienen estas grandes empresas (Grané \& Bartolomé, 2008). Hay un elemento digital muy importante que se debe utilizar: la etiqueta (\#), denominada hashtag, como un instrumento que se puede implementar para posicionar el nombre de la compañía, no solo en la red social Facebook, sino como una tendencia en distintas redes. Si bien reconocen que se puede utilizar para colocar una campaña de salud, esta opción que aplica la empresa Roche debería ser implementada por los grandes consorcios para colocarse y facilitar su búsqueda en el espacio virtual. En este sentido, pareciera que la interactividad como un rasgo de CR no se potencializa.

De acuerdo con Smith (citado en Glozer et al., 2018) es importante mejorar el valor percibido por las audiencias sobre la marca logrando mayor empatía. Se aprecia que, para esta muestra, la imagen de la marca es un área de mejora que las empresas deben trabajar (concretamente) la credibilidad a través de recursos y herramientas digitales, así como poner atención en la estructura de las herramientas para mostrar congruencia con la identidad gráfica que manejan dentro de estos elementos visuales que pueden afectar la percepción de los públicos sobre los productos y servicios que se colocan en el mercado y que no se comunican responsablemente.

Para promover la confiabilidad en las audiencias, es necesario que las empresas incluyan las fuentes de información que consultaron para la integración de sus infográficos; o bien comenten que la información publicada es resultado de las investigaciones que ellos mismos han realizado, indicador sugerido por los autores Kriscautzky \& Ferreriro (2014) y Vázquez, (2017). Esta tendencia se complementa con los subindicadores de validez y fuentes de la comunicación digital responsable, en el que se encontró que es una práctica recurrente que las empresas no mencionen como sustento de la información una autori- 
dad en el área, ni la vigencia de la información. Es fundamental que (a pesar de ser compañías con un nicho de mercado) ese hecho no sea el argumento que justifique a estas empresas como autoridades en la investigación en salud como lo postulan Muñoz del Bosque (2017) y Tabakman (2011).

Asimismo, resulta elemental que las empresas inserten otros elementos digitales como los hipervínculos. Estos recursos pueden ayudar a sustentar la publicación que las compañías hacen en sus redes sociales de manera más responsable y con ello propiciar una $\mathrm{CR}$ en salud, corporativa y digital que promueva especialmente los rasgos de honestidad y transparencia (Hernández-Flores, 2018), aunque visto bajo los resultados no se promueve el diálogo ni la empatía a partir de la comunicación pública de los productos comunicativos, por lo que la comunicación se sigue apreciando unidireccional, a pesar de la apertura a redes sociales de las organizaciones farmacéuticas en este caso.

\section{Conclusiones}

A partir de lo expuesto, se puede concluir que la infografía (como herramienta digital) permite realizar una CR siempre que se integren de manera consistente los rasgos esenciales que propone el modelo, a través del énfasis en la conceptualización de los subcampos. Resulta importante utilizar los infográficos y conocer el entorno en que pueden publicarse, como es el caso de las redes sociales, para así lograr mayor empatía e interactividad con los públicos. Aprovechar estos espacios coadyuva a reforzar los nichos de mercado de las organizaciones y a incrementar el número de sus consumidores bajo una perspectiva ética y de uso útil a la sociedad.

La observación que se realizó en este estudio se circunscribe a páginas oficiales dirigidas al público mexicano. Por ello, habría que realizar otros estudios que permitan identificar la presencia de CR en los mismos subcampos, pero en otras páginas oficiales con enfoque global o regional, a partir de que se atiende a otras audiencias y otros sectores. Más aún, es preciso verificar que este tipo de observaciones se pueden aplicar a diversas ramas económicas, con la intención de valorar el ejercicio de CR en sus distintos subcampos, que se realiza de forma cotidiana, a través de las distintas herramientas digitales que existen en los ambientes digitales para comunicar mensajes de forma breve y efectiva. 
La comunicación corporativa y la comunicación digital pueden llevarse a cabo en el marco de una comunicación responsable, con la intención de fortalecer una imagen y reputación más sólidas de la organización. La conjunción de los elementos propios de cada una de ellas permite enfocar estrategias de comunicación corporativa-digital más pertinentes y exitosas en los contextos actuales, sin dejar de lado a las empresas como un agente económico y social que propician una continua venta no sólo de su imagen sino también de sus productos y sus servicios.

\section{Fuentes consultadas}

Apolo, D., Báez, V., Pauker, L., \& Pasquel, G. (2017). Gestión de Comunicación Corporativa: consideraciones para el abordaje de su estudio y práctica. Revista Latina de Comunicación Social, 72, 521-539. https:// doi.org/10.4185/RLCS-2017-1177en

Barriga, P., \& Andrade, J. (2012). Herramientas digitales para la construcción de conocimiento. Sistemas \& Telemática, 10(22), 115-124. https://doi. org/10.18046/syt.v10i22.1267

Boshoff, H. (2017). An exploration of rounding theories of responsible communication: A literature review. Responsible Communication. https://responsible-communication.co.za/research/paper-literature-review-a-philosophy/

Comba, S., \& Toledo, E. (2008). La comunicación digital: Nuevos ambientes de interacción en la formación universitaria. Razón y Palabra, 63. https://www.redalyc.org/pdf/1995/199520798013.pdf

Costa, J. (1995). Comunicación corporativa y revolución de los servicios. Ediciones Ciencias Sociales.

De Pablos, J. (1998). Siempre ha habido infografía. Revista Latina de Comunicación Social, 5. http://www.revistalatinacs.org/a/latina_art48. pdf 
Excélsior. (2019, Mayo24). Es oficial, a los mexicanos les fascina Facebook.Excelsior. https://www.excelsior.com.mx/hacker/2017/05/24/1165396

García García, F. (2006). Contenidos educativos digitales: Construyendo la sociedad del conocimiento. Revista de Tecnologías de la Información y Comunicación Educativas, 6, 1-29. http://reddigital.cnice.mec.es/6/ Articulos/pdf/Articulos_1.pdf

García-Marzá, D. (2017). From ethical codes to ethical auditing: An ethical infrastructure for social responsibility communication. El Profesional de la Información, 26(2), 268-276. http://www.elprofesionaldelainformacion.com/contenidos/2017/mar/13.pdf

Gil, L. (2015, Mayo 8). Impacto de las redes sociales en el sector salud. Social Media en investigación. https://socialmediaeninvestigacion.com/ impacto-redes-sociales-salud/

Glozer, S., Caruana, R., \& Hibbert, S. (2018). The Never-Ending Story: Discursive Legitimation in Social Media Dialogue. Organization Studies, 40(5), 625-650. https://doi.org/10.1177/0170840617751006

González-Pacanowski, T., \& Medina, P. (2009). Valor comunicacional de la infografía. El Profesional de la Información, 18(4), 413-420. http://www. elprofesionaldelainformacion.com/contenidos/2009/julio/08.pdf

Grané, A., \& Bartolomé, A. (2008). Herramientas digitales en una web ampliada. http:/www.lmi.ub.edu/eroo/docs/abp_mgo_2008.pdf

Hernández-Flores. H. (2018, Julio). La comunicación responsable como un eje de investigación de la comunicación organizacional ante los entornos politicos, gubernamentales y corporativas en América Latina [Ponencia]. Encuentro "Escuchando nuestras voces: Perspectivas latinoamericanas en Comunicación Organizacional", San José, Costa Rica.

IgeaHub. (2019, Marzo 7). Top 10 compañias farmacéuticas 2018 a nivel mundial. Aimfa. https:/www.aimfa.es/top-10-companias-farmaceuticas-2018-nivel-mundial/\#comments 
Kriscautzky, M., \& Ferreriro, E. (2014). La confiabilidad de la información en Internet: criterios declarados y utilizados por jóvenes estudiantes mexicanos. Educação e Pesquisa, 40(4), 913-934. http://dx.doi. org/10.1590/s1517-97022014121511

Latuff, L., \& Nakhoul, S. (2008). La comunicación digital en la sociedad del conocimiento. https://unexpo.files.wordpress.com/2012/02/sociedadconocimiento.pdf

Maldonado, M. (2016). Facebook y sus 61 millones de usuarios en México. El Financiero. https://www.elfinanciero.com.mx/blogs/historias-de-negoceos/facebook-y-sus-61-millones-de-usuarios-en-mexico.html

Marín, B. (2009). La infografía digital, una nueva forma de comunicación. http:/www.gabinetecomunicacionyeducacion.com/sites/default/files/ field/adjuntos/la_infografia_digital_una_nueva_forma_de_comunicacion.pdf

Martínez, A. (2018, Mayo 17). 7 gráficos sobre los usuarios de internet en México del 2018. El economista. https://www.eleconomista.com. $\mathrm{mx} /$ tecnologia/7-graficos-sobre-los-usuarios-de-internet-en-Mexico-en-2018-20180517-0077.html

Muñoz del Bosque, J. (2017, Abril 13). El uso de infografías en temas de salud. Universidad Intercontinental. http://www.uic.edu.mx/uso-infografias-temas-salud/\#prettyPhoto

Rincón, Y. (2014). Comunicación corporativa, relaciones públicas y logística en la dinámica organizacional. Encuentros, 1, 47-58. http://www.scielo.org.co/pdf/encu/v12n1/v12n1a04.pdf

Rivera, P. (2019). Infografías de salud publicadas por organizaciones y autoridades sanitarias en la red social Pinterest. RITI Revista de Investigación en Tecnologías de la Información 7(13), 92-100.

Salaverría, R. (2004). Diseñando el lenguaje para el ciberperiodismo. Chasqui. Revista Latinoamericana de Comunicación, 86, 38-45. https:// doi.org/10.16921/chasqui.v0i86.1517 
Smith, K. (2019, Abril 29). 116 estadísticas interesantes de las redes sociales. https://www.brandwatch.com/es/blog/116-estadisticas-de-las-redes-sociales/

Tabakman, R. (2011). La salud en los medios. Medicina para periodistas... Periodismo para médicos. International Medical Publishing.

Vázquez, K. (2017). Uso académico de dispositivos tecnológicos por los estudiantes de Ingeniería Industrial de la Universidad Peruana de Ciencias Aplicadas [Tesis de licenciatura]. Cybertesis Repositorio de Tesis Digitales, Universidad Nacional Mayor de San Marcos. http:/cybertesis.unmsm.edu.pe/handle/cybertesis/7140

Yepes, J. (2006). Apuntes sobre comunicación digital. Revista Virtual Universidad Católica del Norte, 19. https://revistavirtual.ucn.edu.co/index. $\mathrm{php} /$ RevistaUCN/article/view/195/375 